\title{
Mutational analysis of BRCA1 and BRCA2 in northwest Chinese breast cancer patients
}

\author{
Ting Wang", Juliang Zhang", Jingjing Xiao, Meiling Huang, Nanlin Li, Rui Ling \\ Department of Thyroid, Breast and Vascular Surgery, Xijing Hospital, The Fourth Military Medical University, Xi'an 710032, China \\ Contributions: (I) Conception and design: R Ling, T Wang; (II) Administrative support: J Zhang, N Li; (III) Provision of study materials or patients: \\ T Wang, J Zhang, N Li; (IV) Collection and assembly of data: M Huang, J Xiao; (V) Data analysis and interpretation: M Huang; (VI) Manuscript \\ writing: All authors; (VII) Final approval of manuscript: All authors. \\ \#The authors contributed equally to this work. \\ Correspondence to: Rui Ling; Nanlin Li. Department of Thyroid, Breast and Vascular Surgery, Xijing Hospital, The Fourth Military Medical \\ University, Xi’an 710032, China. Email: lingruiaoxue@126.com; linanlingo@126.com.
}

Background: BRCA1 and BRCA2 are the most well-known susceptibility genes in breast cancer, indicating high-risk breast cancer families and influencing both treatment options. However, data of BRCA mutation in Chinese breast cancer population was limited. Here we explored the BRCA1/2 mutation status and analyzed their clinicopathological relationships among breast cancer patients with high hereditary risk in northwest China.

Methods: Breast cancer patients admitted to Xijing Hospital, between November 2015 and May 2016, with high hereditary risk were recruited. Fresh peripheral venous blood samples were collected for BRCA1/2 gene screening. Risk factors for BRCA1/2 mutations were studied via single-factor analysis and multivariable logistic analysis. Furthermore, we reviewed the literature and discussed the possible mechanism of the mutant genome types.

Results: Eighty-two patients were enrolled in the study. Twenty (24.4\%) of them were found with BRCA1/2 mutation, including 8 BRCA1 mutation and 13 BRCA2 mutation. BRCA1 and BRCA2 co-mutation was observed in only one case. The mutant genome types included pathogenic variant (4/82), potential pathogenic variant (4/82), beneficial mutations (8/82), and chemotherapy sensitivity-related mutations (5/82). Prognosisrelated mutations were enriched in $B R C A 2$ gene, while drug-sensitive related mutations were always observed in BRCA1 gene. Multiple logistic analysis showed that HER2 [odds ratio (OR) 4.58; 95\% confidence interval (CI), 1.182-17.74; $\mathrm{P}=0.028$ ) might be independent factor for BRCA1/2 mutation.

Conclusions: The incidence and feature of BRCA1/2 mutation in our center was similar to that in other regions. HER2 expression was independent factor for BRCA1 and BRCA2 mutation. BRCA2 T/-, BRCA2 A/-, BRCA2 G/- and BRCA2 C/-mutation subtypes might be potential harmful mutations for Chinese breast cancer population.

Keywords: BRCA1; BRCA2; genomic screening; breast cancer; literature review

Submitted Nov 27, 2018. Accepted for publication Aug 08, 2019.

doi: $10.21037 /$ tcr.2019.08.32

View this article at: http://dx.doi.org/10.21037/tcr.2019.08.32

\section{Introduction}

Breast cancer is still the most commonly diagnosed cancer (2.08 million new cases) and the leading cause of cancer death (0.66 million deaths) among females (1). Consistently, in China, breast cancer statistics is identical with that worldwide. Approximately $11 \%$ of worldwide breast cancer occurs in China and that the incidence has increased rapidly in recent decades (2). However, breast cancer in China is not comprehensively understood compared with 
Westernized countries.

About 5-10\% of breast cancer burden follows a Mendelian inheritance pattern and is characterized as hereditary (3). The breast cancer-associated genes BRCA1 on chromosome $17 \mathrm{q}$ and BRCA2 on chromosome $13 \mathrm{q}$ are the most well-known breast cancer susceptibility genes, indicating from high-risk breast cancer families and influencing both treatment options and clinical management $(4,5)$. In United States, the average cumulative risks of breast cancer in BRCA1 and BRCA 2 mutation carriers by age 70 years are in the ranges of $60-70 \%$ and $45-55 \%$ (6). However, multigene panel testing of breast cancer predisposition genes have been extensively conducted in Europe and America, which is relatively rare in Asia region. In China, rare large-scale research has been conducted to examine the BRCA1/2 mutations. In 2015, we participated into the multicenter study by $\mathrm{Li}$ et al. and assessed the frequency of germline mutations in 40 cancer predisposition genes (7). Finally, we acquired 159 patients with BRCA1/2 mutations among 937 Chinese breast cancer patients with high hereditary risk. However, the characteristics of BRCA1/2 mutation subtypes, as well as its association with clinicopathological features need further discussion.

In this study, we reported the screening results of BRCA1/2 mutation in our center and analyzed the association of BRCA1/2 mutation with clinicopathological characteristics. Based on the special genome mutation, we reviewed the literature and discussed their possible mechanism in breast cancer incidence and prognosis.

\section{Methods}

\section{Participants}

Between November 2015 and May 2016, breast cancer patients admitted to Xijing Hospital with high hereditary risk were recruited. Inclusion criteria: (I) onset age $\leq 35$ years (early-onset breast cancer); (II) at least one first or seconddegree relative with breast cancer, ovarian cancer (OC), primary peritoneal cancer, or fallopian tube carcinoma; (III) two primary breast cancer; (IV) male breast cancer; (V) breast cancer with OC, fallopian tube carcinoma or primary peritoneal cancer. This protocol was approved by the Ethics Committee of the Xijing Hospital of The Fourth Military Medical University (No. KY20150916-4) and undertaken in accordance with the Good Clinical Practice guidelines and the Declaration of Helsinki. All patients were fully consented and asked to provide written informed consent before enrollment.

\section{BRCA1/2 screening}

Participants were asked for $5 \mathrm{~mL}$ fresh peripheral venous blood, which was transferred into a coded Ethylenediaminetetraacetic Acid (EDTA) tube at $4{ }^{\circ} \mathrm{C}$. Then, the collected blood samples were sent to Annoroad Gene Technology (Beijing, China) Co. Ltd. for gene testing on an Illumina HiSeq 2500 platform (Illumina, San Diego, CA, USA), as previous described (7). The transcripts of BRCA1 and BRCA2 were NM_007294 and NM_000059, including 49 coding regions, 160 thousand of nucleotide sites. The main endpoints were single base polymorphisms (SNPs) in gene coding region and the base sequence insertion or deletion. Bioinformatics analysis was used to obtain mutant sites. BRCA1/2 mutations were explained based on the references included in comprehensive database (ClinVar and BIC database), clinical practice guideline and the latest medical papers.

\section{Statistical analysis}

SPSS 22.0 for windows was used for statistical analysis. All participants were followed up by specified research nurses and there are two investigators independently extracted the data using a predesigned data extraction form. Normal descriptive data were represented by mean \pm standard deviation. Student's $t$-test was used to compare the mean after checking the homogeneity of variance. Enumeration data was compared using $\chi^{2}$ test, and unadjusted odds ratio and adjusted odd ratio were estimated by logistic regression for each indictor. $\mathrm{P}<0.05$ was considered statistically significant.

\section{Results}

\section{Baseline characteristics}

Between November 2015 and May 2016, 82 patients (77 females and 5 males) were assessed for eligibility. The basic features were presented in Table 1. The average age was $35.7 \pm 9.04$ years old. For menopausal status, $76(92.7 \%)$ patients were premenopausal, while $6(7.3 \%)$ of them were postmenopausal. Besides, the expression of ER (estrogen receptor), PR (progesterone receptor), HER2 (human epidermal growth factor receptor type 2) and Ki67 were investigated. Enrolled patients were proved with high 
Table 1 Baseline characteristics

\begin{tabular}{|c|c|}
\hline Item & Data $(\mathrm{N}=82)$ \\
\hline \multicolumn{2}{|l|}{ Sex } \\
\hline Female & 77 (93.9\%) \\
\hline Male & $5(6.1 \%)$ \\
\hline \multicolumn{2}{|l|}{ Age } \\
\hline Average & $35.7 \pm 9.04$ \\
\hline Median & 34 [8-64] \\
\hline BMI & $22.8 \pm 3.29$ \\
\hline \multicolumn{2}{|l|}{ Marriage } \\
\hline Yes & 77 (93.9\%) \\
\hline No & $5(6.1 \%)$ \\
\hline \multicolumn{2}{|l|}{ Lactation } \\
\hline Yes & $57(69.5 \%)$ \\
\hline No & $25(30.5 \%)$ \\
\hline \multicolumn{2}{|l|}{ Menopausal status } \\
\hline Premenopause & $76(92.7 \%)$ \\
\hline Postmenopause & $6(7.3 \%)$ \\
\hline \multicolumn{2}{|l|}{ Ethnicity } \\
\hline Han nationality & $80(97.6 \%)$ \\
\hline Others & $2(2.4 \%)$ \\
\hline \multicolumn{2}{|l|}{ Lesion } \\
\hline Bilateral & $1(1.2 \%)$ \\
\hline Unilateral & $81(98.8 \%)$ \\
\hline \multicolumn{2}{|l|}{ Menstruation } \\
\hline Age of menarche & $13[11-17]$ \\
\hline Menstrual cycle & 28 [22-30] \\
\hline \multicolumn{2}{|l|}{ Estrogen receptor } \\
\hline Positive & $54(65.9 \%)$ \\
\hline Negative & $28(34.1 \%)$ \\
\hline \multicolumn{2}{|l|}{ Progesterone receptor } \\
\hline Positive & $50(61.0 \%)$ \\
\hline Negative & $32(39.0 \%)$ \\
\hline \multicolumn{2}{|l|}{ HER2 } \\
\hline Positive & $32(39.0 \%)$ \\
\hline Negative & $50(61.0 \%)$ \\
\hline \multicolumn{2}{|l|}{ Ki67 } \\
\hline$\leq 20$ & $28(34.1 \%)$ \\
\hline$>20$ & $54(65.9 \%)$ \\
\hline \multicolumn{2}{|l|}{ Pathology } \\
\hline Carcinoma in situ & $7(8.5 \%)$ \\
\hline Invasive carcinoma & $69(84.1 \%)$ \\
\hline Others & $6(7.3 \%)$ \\
\hline \multicolumn{2}{|l|}{ Family cancer history } \\
\hline Family breast cancer history & $23(28.0 \%)$ \\
\hline Family other cancer history & $35(42.7 \%)$ \\
\hline
\end{tabular}

hereditary risk. Family breast cancer history and other cancer history were found in $23(28.0 \%)$ and $35(42.7 \%)$ of them.

\section{Results of BRCA1/2 mutation}

Twenty participants (24.4\%) were found with BRCA1/2 mutation among 82 patients with high risk (Table 2). Eight patients were detected with BRCA1 mutation, 13 patients were detected with BRCA2 mutation. There is only one case with both BRCA1 and BRCA2 mutation BRCA2: c.2971A>G (A/G type) mutation indicating good prognosis was found in 8 participants. Mutations about drug-sensitivity, including BRCA1: c.4837A>G (G/G type) and BRCA1: c.2612C>T (T/T type), were explored in 5 patients. G/G genome type and $T / T$ genome type seem to present together. Pathogenic variant (BRCA1 c.4485-2A $>C$, BRCA1 c.5470-5477del, BRCA1: c.190T>C or BRCA2: c. $3109 \mathrm{C}>\mathrm{T}$ ) and potential pathogenic variant (BRCA2: c. 31 delT, BRCA2: c.6408delA, BRCA2: c.6705delG or BRCA2: c. $677 \mathrm{delC})$ were detected in 8 participants. Above all, we found that prognosis-related mutations were enriched in $B R C A 2$ gene, while drug-sensitive related mutations were always observed in BRCA1 gene.

\section{Description of the mutation types in ClinVar and BIC databases}

Searching the mutant genomic types in ClinVar and BIC databases, we found some potential novel mutant types in BRCA2 gene, such as BRCA2 c.31delT, BRCA2 c.6408delA, BRCA2 c.6705delG and BRCA2 c.677delC genome types (Table 3).

\section{Association of BRCA1/2 mutation with clinicopathological characteristics}

To explore the relationship between BRCA1/2 mutation and clinical features, we classified participants into mutation group and wild group. As shown in Table 4, HER2 expression, family cancer history and family breast/ OC history were significantly different between BRCA1/2 mutation group and BRCA1/2 wild group. Multiple logistic analysis showed that HER2 [odds ratio (OR) 4.58; $95 \%$ confidence interval $(\mathrm{CI}), 1.182-17.74 ; \mathrm{P}=0.028]$ was independent factor for BRCA1/2 mutation (Table 5). Among 32 patients with positive HER2, only 9\% (3/32) of them were detected with BRCA1 or BRCA2 mutation. But 
Table 2 List of patients with BRCA1/2 mutation

\begin{tabular}{|c|c|c|c|c|c|c|c|c|c|}
\hline No. & Sex & BMI & Age & Pathology & $\begin{array}{l}\text { Family cancer } \\
\text { history }\end{array}$ & $\begin{array}{l}\text { Cancer } \\
\text { type }\end{array}$ & Mutation & Genome type & Effects \\
\hline 1 & Female & 23.37 & 41 & IBC & Yes & $\mathrm{OC}$ & BRCA1: c.4485-2A>C & $\mathrm{A} / \mathrm{C}$ & DM \\
\hline 2 & Female & 24.35 & 30 & IBC + IDC & No & - & BRCA1: c.5470-5477del & TGCCCAAT/- & DM \\
\hline 3 & Female & 27.39 & 43 & IBC & Yes & $\mathrm{BC}$ & BRCA1: c.190T>C & $\mathrm{T} / \mathrm{C}$ & $\mathrm{DM}$ \\
\hline 5 & Female & 30.12 & 47 & IDC & Yes & $\mathrm{OC}$ & $\begin{array}{l}\text { BRCA1: c. } 4837 A>G \\
\text { BRCA1: c. } 2612 C>T\end{array}$ & G/G; T/T & $A ; B$ \\
\hline 6 & Female & 20.06 & 62 & IDC & Yes & $\mathrm{OC}$ & $\begin{array}{l}\text { BRCA1: c. } 4837 A>G \\
\text { BRCA1: c. } 2612 C>T\end{array}$ & G/G; T/T & $A ; B$ \\
\hline 9 & Female & 21.88 & 34 & IBC & No & - & BRCA2: c. $2971 A>G$ & $A / G$ & GP \\
\hline 10 & Female & 20.69 & 38 & IBC & Yes & $\mathrm{BC}$ & BRCA2: c. $2971 A>G$ & $A / G$ & GP \\
\hline 11 & Female & 24.24 & 35 & IBC & No & - & BRCA2: c. $2971 A>G$ & $A / G$ & GP \\
\hline 12 & Female & 21.48 & 39 & IBC & Yes & $\mathrm{BC}$ & BRCA2: c. $2971 A>G$ & $A / G$ & GP \\
\hline 13 & Female & 23.74 & 31 & $\mathrm{MBC}$ & No & - & BRCA2: c. $2971 A>G$ & $\mathrm{~A} / \mathrm{G}$ & GP \\
\hline 14 & Female & 22.10 & 38 & IBC & No & - & BRCA2: c. $2971 A>G$ & $A / G$ & GP \\
\hline 15 & Female & 21.48 & 28 & IBC & Yes & $\mathrm{BC}$ & $\begin{array}{l}\text { BRCA2: c. } 2971 \mathrm{~A}>\mathrm{G} ; \\
\text { BRCA1: c. } 4837 \mathrm{~A}>\mathrm{G} ; \\
\text { BRCA1: c. } 2612 \mathrm{C}>\mathrm{T}\end{array}$ & A/G;G/G;T/T & GP;A;B \\
\hline 20 & Female & 20.32 & 59 & IBC & Yes & $\mathrm{BC}^{*} 4$ & BRCA2: c.3109C>T & $\mathrm{C} / \mathrm{T}$ & DM \\
\hline
\end{tabular}

IBC, invasive breast carcinoma; IDC, invasive ductal carcinoma; MBC, mucinous breast carcinoma; OC, ovarian cancer; BC, breast cancer; GC, gastric cancer; EC, esophagus cancer; DM, detrimental mutation; PDM, potential detrimental mutation; GP, good prognosis; A, sensitive to platinum drugs; $B$, prolonged survival for cisplatin + paclitaxel regimen.

for 50 cases of HER2 negative breast cancer patients, 34\% $(17 / 50)$ were found mutant BRCA1 or BRCA2 gene.

\section{Discussion}

BRCA1/BRCA2 mutations have been identified as main contributor of hereditary breast cancer, increasing the lifetime risk of breast cancer in women (8). However, this paradigm has not been studied extensively and accurately in China. In this study, we investigated the BRCA1/2 mutation rate and mutation features for breast cancer patients in northwest China. The mutation rate of BRCA1/2 in high hereditary risk breast cancer patients was $24.4 \%$, which was similar to that in other regions. In 2015, Riahi et al. estimate $25 \%$ pathogenic mutations in BRCA1/2 genes in early-onset and familial breast/OC among Tunisian women (9). In 2016, Cao et al. observed a total mutation frequency of $23.3 \%$ in BRCA1 and BRCA2 genes among patients in eastern China (10). Differently, BRCA2 mutations seem to be a few more than BRCA1 mutations (11). In 
Table 3 Searching of ClinVar and BIC databases

\begin{tabular}{|c|c|c|c|c|c|c|c|}
\hline Gene & Mutant & Exon & Nucleotide & AA change & BIC entries & Clinvar entries & Novel genome \\
\hline \multirow{3}{*}{ BRCA1 } & c.5470-5477del & 23 & $5470-5477$ & Frameshift & 2 & 3 & No \\
\hline & c. $190 \mathrm{~T}>\mathrm{C}$ & 64 & 190 & Cys to Arg & 14 & 4 & No \\
\hline & c. $4837 A>G$ & 15 & 4837 & Ser to Gly & None & None & No \\
\hline \multirow[t]{4}{*}{$B R C A 2$} & c. $3109 \mathrm{C}>\mathrm{T}$ & 11 & 3109 & p.Q1037X & 14 & 6 & No \\
\hline & c. $2971 A>G$ & 11 & 2971 & Asn to Asp & None & None & No \\
\hline & c.31delT & - & 31 & Frameshift & None & None & Yes \\
\hline & c.6408delA & - & 6408 & Frameshift & None & None & Yes \\
\hline
\end{tabular}

2013, Blay et al. found 59 (23\%) families with pathogenic germ line mutation, 39 in BRCA1 and 20 in BRCA2, in hereditary breast and OC families from Asturias (Northern Spain) (12). However, this is a very selective cohort. More convincing data of BRCA1/2 mutations should be achieved in cohort with larger samples.

In this study, we found 8 pathogenic variants in $B R C A 1$ and $B R C A 2$ genes, some of which have been reported previously. In 2001, BRCA1: c.4485-2A>C (BRCA1 A/ $\mathrm{C}$ genome type) alteration was found among OC families in Japan and was determined as harmful mutation (13). Mutation of BRCA1: c.5470-5477del (TGCCCAAT/type) has been observed in several studies. In 2004, Choi et al. found BRCA1: c.5470-5477del mutation and described it as c.5589del8, in Korean breast cancer families (14). Similarly, BRCA1: c.5470-5477del mutation was detected in 2 out of 645 women from Shanghai, China (15). In 2007, BRCA1: c.5470-5477del mutations were observed in several cases of breast cancer patients and were regarded as the possible founder mutations for Chinese population (16). As founder mutations of Italian people, the detrimental function of BRCA1: c.190T>C (BRCA1 T/C genome type) mutation was verified in two studies from Italy $(17,18)$. BRCA2: c.3109C $>$ T (BRCA2 C/T genome type) mutation was explored and was regarded as the founder mutations of Southern Chinese people (19-21). Importantly, 4 potential harmful mutations, including BRCA2: c.31delT (T/-), BRCA2: c.6408delA (A/-), BRCA2: c.6705 delG (G/-) and BRCA2: c.677delC (C/-) were detected in the study, which have never been reported before. In 2015, Rebbeck et al. exclaimed that c.31delT, c.6408delA, c.6705delG and c.677delC genome types located in BRC domain (c.3006-6255) and DNA binding domain (c.7437-8001) of $B R C A 2$ gene (16). Frame-shifting mutation induced sequence changing of DNA binding domain and $\mathrm{OB}$ (oligonucleotide-binding) folds domain in BRCA2 gene was the possible mechanism. DNA binding domain and $\mathrm{OB}$ folds domain have been reported to participate into the repair of double-strand DNA breaks (DSBs) by homologous recombination (22).

BRCA1 gene, involving homologous recombination, nonhomologous end joining, and mismatch repair, plays crucial role in regulating DNA damage induced by DNAdamaging agents such as platinum (23). Patients with lower BRCA1 expression obtain better survival after platinumbased neoadjuvant chemotherapy (24). Herein, two BRCA1 genotypes (BRCA1: c.4837A>G and BRCA1: c.2612C>T) were detected, indicating better chemotherapy sensitivity. Similarly, Du et al. found that patients with BRCA1: c. $4837 \mathrm{~A}>\mathrm{G}(\mathrm{G} / \mathrm{G})$ mutation achieved a better response to chemotherapy and a decreased risk of death in advanced NSCLC patients (25). BRCA1: c.2612C $>\mathrm{T}(\mathrm{T} / \mathrm{T})$ mutation was also associated with better sensitivity to taxane and cisplatin regimen. In 2010, Shim demonstrated significant prolongation of overall survival (OS) and progressionfree survival (PFS) in advanced gastric cancer patients with BRCA1 T/T mutation, after treating with taxane and cisplatin (26). For non-small cell lung cancer patients treated with first-line paclitaxel-cisplatin chemotherapy, BRCA1 T/T mutation was proved as modest prognostic 
Table 4 Relationship between BRCA1/2 mutation and clinicopathological characteristics

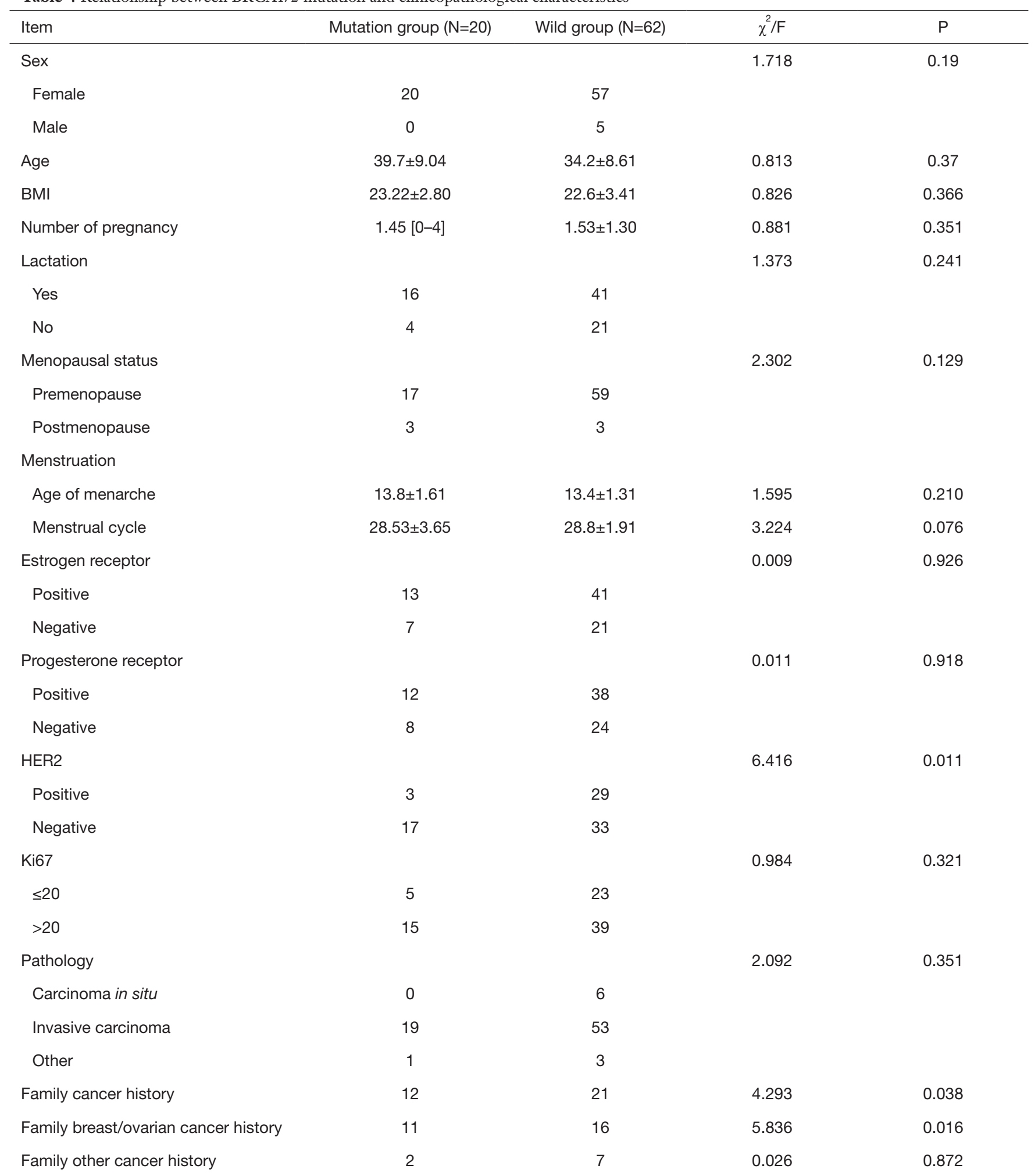


Table 5 Multifactor logistic analysis

\begin{tabular}{|c|c|c|c|c|c|c|c|c|}
\hline Variable & Ref & ence & $\beta$ & SD & Wald & $\mathrm{P}$ & OR & $95 \% \mathrm{Cl}$ \\
\hline Family cancer history & Yes & No & 0.029 & 1.188 & 0.001 & 0.98 & 0.971 & $0.095-9.968$ \\
\hline Family breast/ovarian cancer history & Yes & No & 1.136 & 1.192 & 0.909 & 0.34 & 0.321 & $0.031-3.319$ \\
\hline
\end{tabular}

markers (27).

This study has several limitations. First, the sample size was relatively small. Second, there is no follow-up data because of the short follow-up period. With followup continued, the final prognosis and survival data will be gained. Third, only a limited number of SNPs in BRCA1 and $B R C A 2$ genes were enrolled into detection, while the other polymorphisms in these genes may be important.

In conclusion, the BRCA1/2 mutation features in our hospital and the total mutation rate of BRCA1/2 in high hereditary risk breast cancer patients was similar to that in other regions. HER2 expression was independent factor for BRCA1 and BRCA 2 mutation for breast cancer with high risk. Four novel genome types, including BRCA2: c.31delT (T/-), BRCA2: c.6408delA (A/-), BRCA2: c.6705delG (G/-) and BRCA2: c.677delC (C/-), might be potential harmful mutations, which needs further verification.

\section{Acknowledgments}

Funding: This work was funded by National Natural Science Foundation of China (No. 81572917 and 81472598) and Wujieping Foundation (320.6750.13292).

\section{Footnote}

Conflicts of Interest: All authors have completed the ICMJE uniform disclosure form (available at http://dx.doi. org/10.21037/tcr.2019.08.32). The authors have no conflicts of interest to declare.

Ethical Statement: The authors are accountable for all aspects of the work in ensuring that questions related to the accuracy or integrity of any part of the work are appropriately investigated and resolved. This protocol was approved by the Ethics Committee of the Xijing Hospital of The Fourth Military Medical University (No. KY20150916-4) and undertaken in accordance with the Good Clinical Practice guidelines and the Declaration of Helsinki. All patients were fully consented and asked to provide written informed consent before enrollment.

Open Access Statement: This is an Open Access article distributed in accordance with the Creative Commons Attribution-NonCommercial-NoDerivs 4.0 International License (CC BY-NC-ND 4.0), which permits the noncommercial replication and distribution of the article with the strict proviso that no changes or edits are made and the original work is properly cited (including links to both the formal publication through the relevant DOI and the license). See: https://creativecommons.org/licenses/by-nc-nd/4.0/.

\section{References}

1. Bray F, Ferlay J, Soerjomataram I, et al. Global cancer statistics 2018: GLOBOCAN estimates of incidence and mortality worldwide for 36 cancers in 185 countries. CA Cancer J Clin 2018;68:394-424.

2. Li T, Mello-Thoms C, Brennan PC. Descriptive epidemiology of breast cancer in China: incidence, mortality, survival and prevalence. Breast Cancer Res Treat 2016;159:395-406.

3. Economopoulou P, Dimitriadis G, Psyrri A. Beyond BRCA: new hereditary breast cancer susceptibility genes. Cancer Treat Rev 2015;41:1-8.

4. Tanic M, Yanowski K, Gomez-Lopez G, et al. MicroRNA expression signatures for the prediction of BRCA1/2 mutation-associated hereditary breast cancer in paraffinembedded formalin-fixed breast tumors. Int J Cancer 2015;136:593-602.

5. Smith KL, Isaacs C. BRCA mutation testing in determining breast cancer therapy. Cancer J 2011;17:492-9.

6. Chen S, Iversen ES, Friebel T, et al. Characterization of BRCA1 and BRCA2 mutations in a large United States sample. J Clin Oncol 2006;24:863-71.

7. Li J, Jing R, Wei $\mathrm{H}$, et al. Germline mutations in 40 cancer susceptibility genes among Chinese patients with high hereditary risk breast cancer. Int J Cancer 2019;144:281-9.

8. Vos S, van Diest PJ, Moelans CB. A systematic review on 
the frequency of BRCA promoter methylation in breast and ovarian carcinomas of BRCA germline mutation carriers: Mutually exclusive, or not? Crit Rev Oncol Hematol 2018;127:29-41.

9. Riahi A, Kharrat M, Ghourabi ME, et al. Mutation spectrum and prevalence of BRCA1 and BRCA2 genes in patients with familial and early-onset breast/ovarian cancer from Tunisia. Clin Genet 2015;87:155-60.

10. Cao WM, Gao Y, Yang HJ, et al. Novel germline mutations and unclassified variants of BRCA1 and BRCA2 genes in Chinese women with familial breast/ovarian cancer. BMC Cancer 2016;16:64.

11. Kwong A, Shin VY, Ho JC, et al. Comprehensive spectrum of BRCA1 and BRCA2 deleterious mutations in breast cancer in Asian countries. J Med Genet 2016;53:15-23.

12. Blay P, Santamaria I, Pitiot AS, et al. Mutational analysis of BRCA1 and BRCA2 in hereditary breast and ovarian cancer families from Asturias (Northern Spain). BMC Cancer 2013;13:243.

13. Sekine M, Nagata $H$, Tsuji S, et al. Mutational analysis of BRCA1 and BRCA2 and clinicopathologic analysis of ovarian cancer in 82 ovarian cancer families: two common founder mutations of BRCA1 in Japanese population. Clin Cancer Res 2001;7:3144-50.

14. Choi DH, Lee MH, Bale AE, et al. Incidence of BRCA1 and BRCA2 mutations in young Korean breast cancer patients. J Clin Oncol 2004;22:1638-45.

15. Suter NM, Ray RM, Hu YW, et al. BRCA1 and BRCA2 mutations in women from Shanghai China. Cancer Epidemiol Biomarkers Prev 2004;13:181-9.

16. Rebbeck TR, Mitra N, Wan F, et al. Association of type and location of BRCA1 and BRCA2 mutations with risk of breast and ovarian cancer. JAMA 2015;313:1347-61.

17. Willems P, Magri V, Cretnik M, et al. Characterization of the c.190T >C missense mutation in BRCA1 codon 64 (Cys64Arg). Int J Oncol 2009;34:1005-15.

18. Caleca L, Putignano AL, Colombo M, et al. Characterization of an Italian founder mutation in the RING-finger domain of BRCA1. PLoS One

Cite this article as: Wang T, Zhang J, Xiao J, Huang M, Li N, Ling R. Mutational analysis of BRCA1 and BRCA2 in northwest Chinese breast cancer patients. Transl Cancer Res 2019;8(5):1845-1852. doi: 10.21037/tcr.2019.08.32 2014;9:e86924.

19. Kwong A, Wong LP, Wong HN, et al. A BRCA2 founder mutation and seven novel deleterious BRCA mutations in southern Chinese women with breast and ovarian cancer. Breast Cancer Res Treat 2009;117:683-6.

20. Kwong A, Ng EK, Law FB, et al. High-resolution melting analysis for rapid screening of BRCA2 founder mutations in Southern Chinese breast cancer patients. Breast Cancer Res Treat 2010;122:605-7.

21. Kwong A, Ng EK, Wong CL, et al. Identification of BRCA1/2 founder mutations in Southern Chinese breast cancer patients using gene sequencing and high resolution DNA melting analysis. PLoS One 2012;7:e43994.

22. Yang H, Jeffrey PD, Miller J, et al. BRCA2 function in DNA binding and recombination from a BRCA2-DSS1ssDNA structure. Science 2002;297:1837-48.

23. Bonanno L, Costa C, Majem M, et al. The predictive value of BRCA1 and RAP80 mRNA expression in advanced non-small-cell lung cancer patients treated with platinumbased chemotherapy. Ann Oncol 2013;24:1130-2.

24. Yang Y, Xie Y, Xian L. Breast cancer susceptibility gene 1 (BRCA1) predict clinical outcome in platinum- and toxal-based chemotherapy in non-small-cell lung cancer (NSCLC) patients: a system review and meta-analysis. J Exp Clin Cancer Res 2013;32:15.

25. Du Y, Su T, Zhao L, et al. Associations of polymorphisms in DNA repair genes and MDR1 gene with chemotherapy response and survival of non-small cell lung cancer. PLoS One 2014;9:e99843.

26. Shim HJ, Yun JY, Hwang JE, et al. BRCA1 and XRCC1 polymorphisms associated with survival in advanced gastric cancer treated with taxane and cisplatin. Cancer Sci 2010;101:1247-54.

27. Lee SY, Kang HG, Yoo SS, et al. Polymorphisms in DNA repair and apoptosis-related genes and clinical outcomes of patients with non-small cell lung cancer treated with first-line paclitaxel-cisplatin chemotherapy. Lung Cancer 2013;82:330-9. 